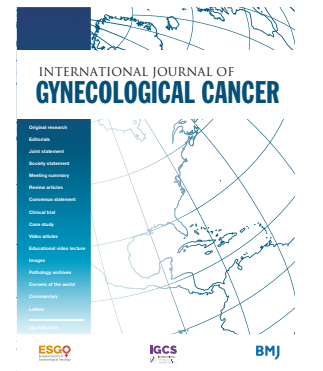

Department of Reproductive Medicine, Chiba University Graduate School of Medicine School of Medicine, Chiba, Japan

\section{Correspondence to} Dr Ayumu Matsuoka, Department of Reproductive Medicine, Chiba University Graduate School of Medicine School of Medicine, Chiba 2638522, Japan; ayumu28ma@ yahoo.co.jp

Accepted 25 March 2021 Published Online First 22 April 2021

\title{
Right diaphragm resection using a ball-type electrode and soft coagulation for advanced ovarian cancer: techniques and tips
}

Ayumu Matsuoka, Shinichi Tate, Satoyo Otsuka, Kyoko Nishikimi, Makio Shozu

Complete resection is important to improve the prognosis of advanced ovarian cancer. The efficacy of the soft coagulation mode built into the VIO system has been reported in hepatic and pancreatic surgeries and in retroperitoneal lymphadenectomy. ${ }^{1-3}$ However, there are no reports or surgical videos regarding the VIO system in cytoreductive surgery. In this video, we demonstrate the use of a balltype electrode of this system for diaphragm resection in advanced ovarian cancer.

VIO 300 D (ERBE Elektromedizin GmbH, Germany) provides the minimum required output depending on tissue resistance. We applied the automatic output control function and the blunt peeling effect of the ball-type electrode to diaphragm stripping. Since the ball shape has a wide contact area with the tissue and a low current density, excessive incision effects can be avoided. In the auto-cut mode of this system, the required current can be supplied instantaneously, and spark discharge can be adjusted to the needs of the situation. In the soft coagulation mode, the automatically controlled low voltage enables effective hemostasis without spark generation, tissue carbonization, or adhesion.

In case 1, involving a 65-year-old woman with stage IIIC ovarian cancer, stripping of the diaphragm was difficult with a conventional electric scalpel due to dissemination and fibrosis. The diaphragmatic peritoneum was stripped smoothly using a ball-type electrode. In case 2, involving a 72-year-old woman with stage IVB ovarian cancer with a large subphrenic tumor invading the liver, we excised the liver with an electric scalpel, and complete hemostasis was achieved by soft coagulation without suture.
The ball-type electrode and soft coagulation of the VIO system helped us perform a smooth resection of the diaphragm and ensure hemostasis in cytoreductive surgery for advanced ovarian cancer.

Contributors AM and ST performed the surgery. SO and KN took the surgical video. AM wrote the manuscript and edited the video. MS edited the manuscript. All authors have approved the final manuscript.

Funding The authors have not declared a specific grant for this research from any funding agency in the public, commercial or not-for-profit sectors.

Competing interests None declared.

Patient consent for publication Not required.

Provenance and peer review Not commissioned; externally peer reviewed.

Data availability statement All data relevant to the study are included in the article.

\section{REFERENCES}

1 Itoh S, Fukuzawa K, Shitomi Y, et al. Impact of the VIO system in hepatic resection for patients with hepatocellular carcinoma. Surg Today 2012;42:1176-82.

2 Akita $\mathrm{H}$, Takahashi $\mathrm{H}$, Gotoh K, et al. Closure method for thick pancreas stump after distal pancreatectomy: soft coagulation and polyglycolic acid felt with fibrin glue. Langenbecks Arch Surg 2015;400:843-8.

3 Matsuoka A, Tate S, Nishikimi K, et al. Efficacy of soft coagulation in retroperitoneal lymphadenectomy for ovarian cancer. Gynecol Oncol 2018;149:430-1.

\section{GYNECOLOGICAL CANCER}

Right diaphragm resection using ball-type electrode and soft coagulation for advanced ovarian cancer: techniques and tips Chiba University Hospital, Japan Ayumu Matsuoka, Shinichi Tate, Satoyo Otsuka, Kyoko Nishikimi, Makio Shozu

Check for updates

(C) IGCS and ESGO 2021. No commercial re-use. See rights and permissions. Published by BMJ.

To cite: Matsuoka A, Tate S, Otsuka S, et al. Int J Gynecol Cancer 2021;31:1087.

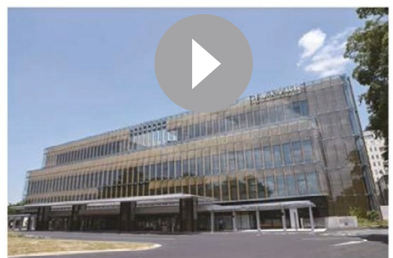

@IJGConline 